\title{
The antioxidant effects of garlic saponins protect PC12 cells from hypoxia-induced damage
}

\author{
Hong Luo ${ }^{1,2,3}$, Jian Huang ${ }^{2,3}$, Wei-Gong Liao ${ }^{2,3}$, Qing-Yuan Huang ${ }^{2,3}$ and Yu-Qi Gao ${ }^{2,3,4 *}$ \\ ${ }^{1}$ Department of High Altitude Military Hygiene, College of High Altitude Medicine, Third Military Medical University, \\ Chongqing 400038, China \\ ${ }^{2}$ Department of Pathophysiology and High Altitude Physiology, College of High Altitude Medicine, Third Military Medical \\ University, Chongqing 400038, China \\ ${ }^{3}$ Key Laboratory of High Altitude Medicine, Ministry of Education, Chongqing 400038, China \\ ${ }^{4}$ The Key Laboratory of High Altitude Physiology and High Altitude Disease, PLA, Chongqing 400038, China \\ (Received 25 May 2010 - Revised 13 October 2010 - Accepted 19 October 2010 - First published online 21 December 2010)
}

\begin{abstract}
Hypoxia frequently occurs under several different cellular circumstances. Excess reactive oxygen species that are induced by hypoxia may result in cell injury and dysfunction. Recently, garlic has been found to possess some biological and pharmacological activities. The present study examined the effects of garlic saponins (GSP) on the survival of differentiated PC12 (dPC12) cells and the oxidative-antioxidant system. dPC12 cells were exposed to $2 \% \mathrm{O}_{2}$ in order to establish a neuronal insult model. Cell viability was determined by the 3-(4,5dimethylthiazol-2-yl)-2,5-diphenyl tetrazolium bromide reduction assay and lactate dehydrogenase (LDH) release assay. The expression of selected genes (catalase (CAT), p65 and neuron-specific class III $\beta$-tubulin) was evaluated by real-time PCR and immunoblot assays. CAT activity, malondialdehyde (MDA) and 8-hydroxy-deoxyguanosine (8-OH-dG) concentrations were also determined. The data showed that hypoxia dramatically damaged dPC12 cells, while treatment with approximately $5 \times 10^{-2}-10 \mathrm{ng} / \mathrm{ml} \mathrm{GSP}$ improved cell viability, decreased LDH leakage and caused the cells to maintain neuronal-like characteristics in hypoxia. The production of MDA and 8-OH-dG was attenuated by GSP. CAT activity in dPC12 cells pretreated with GSP was higher than that of the hypoxic control. Moreover, GSP up-regulated CAT expression and decreased the total protein expression as well as the nuclear expression of p65 in hypoxic cells. These data indicate that GSP has antioxidant properties that can protect dPC12 cells from hypoxia-induced damage, which may be related to the up-regulation of CAT expression and activity as well as a decrease in the expression and nucleus distribution of p65 through effects on redox-sensitive signalling pathways.
\end{abstract}

Key words: Garlic saponins: Differentiated PC12 cells: Hypoxia: Antioxidants

Hypoxia is a pervasive physiological stimulus that is encountered under various cellular conditions, such as high altitude, physical exercise, pregnancy, ageing, inflammation, cardiovascular and respiratory failures, wounds and even cancer. Moreover, an excessive load of reactive oxygen species (ROS) generated under hypoxic conditions may result in cell injury and dysfunction ${ }^{(1-4)}$.

Garlic is a common food that has been used for the treatment of many diseases, including cancer, CHD and hypercholesterolaemia ${ }^{(5-7)}$. Garlic is known for its production of steroid saponins as well as organosulphur compounds. However, organosulphur compounds are unstable and give rise to transformed products. Saponins are more stable for cooking and storage. Moreover, garlic saponins (GSP) have been found to have some biological and pharmacological activities, including anti-fungal, anti-bacterial, anti-inflammatory and hypocholesterolaemic influences ${ }^{(6,8)}$. Previous studies have shown that garlic, garlic extract and some garlic organosulphur compounds may also have antioxidant effects ${ }^{(9-12)}$; however, no study to date has reported that GSP exhibits these effects.

Oxidative stress affects the structure and function of proteins $^{(13)}$, nucleic acids ${ }^{(14)}$ and lipids ${ }^{(15-18)}$. Moreover, ROS may serve as messengers for the activation of adaptive responses through redox-sensitive signalling pathways, such as NF-кB and mitogen-activated protein kinases

Abbreviations: ARE, antioxidant response element; CAT, catalase; dPC12, differentiated PC12; GSP, garlic saponin; LDH, lactate dehydrogenase; MAPK, mitogen-activated protein kinase; MDA, malondialdehyde; MTT, 3-(4,5-dimethylthiazol-2-yl)-2,5-diphenyl tetrazolium bromide; NGF, nerve growth factor; Nrf2, nuclear factor E2-related factor 2; ROS, reactive oxygen species; TUJ1, neuron-specific class III $\beta$-tubulin.

*Corresponding author: Y.-Q. Gao, fax +8623 68752334, email gaoy66@gmail.com, rona764@hotmail.com 
(MAPK), which regulate the expression of antioxidant genes involved in non-enzymatic and enzymatic antioxidant defences. NF- $\mathrm{KB}$ is an important transcription factor that participates in the regulation of a wide range of biological processes, including cell survival and proliferation. Antioxidant enzymes provide important protective mechanisms against oxidative damage. For example, superoxide dismutase transforms superoxide radicals $\left(\mathrm{O}_{2}^{--}\right)$into $\mathrm{H}_{2} \mathrm{O}_{2}$, the enzyme catalase (CAT) removes $\mathrm{H}_{2} \mathrm{O}_{2}$ and limits the formation of free hydroxyl radicals $(\mathrm{OH} \cdot)$, and glutathione $S$-transferase removes the toxic products formed by ROS damage $^{(19)}$. Among these antioxidant enzymes, CAT is one of the most active catalysts produced in nature.

The PC12 cell line originates from a rat pheochromocytoma and has the ability to transform into various phenotypes based on cell culture conditions. After treatment with nerve growth factor (NGF), native PC12 cells shift their phenotype from proliferating, undifferentiated cells to postmitotic, differentiated, neurite-bearing neurons (dPC12). Therefore, PC12 cells are widely used as a model for the in vitro study of neuron damage resulting from Alzheimer's disease $^{(20)}$, Parkinson's disease ${ }^{(21,22)}$, hypoxia and oxygenglucose deprivation through the use of a special ischaemic device or by treatment with cobalt chloride ${ }^{(23,24)}$. The purpose of the present study was to explore the effects of GSP on the survival of NGF-dPC12 cells and the oxidative-antioxidant system in hypoxia.

\section{Materials and methods}

\section{Preparation of garlic saponins}

An improved method was used for saponin extraction based on the literature ${ }^{(25)}$. GSP was extracted from dried garlic powder by soaking the powder in $65 \%$ aqueous alcohol for $72 \mathrm{~h}$. The alcoholic mixture was centrifuged at $6800 \mathrm{rpm}$ for $20 \mathrm{~min}$ at $4^{\circ} \mathrm{C}$, and the alcohol in the alcoholic extract was removed using a rotary evaporator at $55^{\circ} \mathrm{C}$. The remaining aqueous solution was extracted by incubating the mixture with acetoacetate followed by $n$-butanol. The $n$-butanol extract was then purified on a D101 macroporous (benzene vinyl, apolarity copolymer) resin column (Tian Jin Hai Tian Chemical Industry Company Limited, Tian Jin, China) and eluted with $70 \%$ alcohol. Finally, GSP was purified from the $70 \%$ alcohol eluate by freezedrying the solution and storing it at $-20^{\circ} \mathrm{C}$.

GSP was validated using TLC, the Liebermann-Burchard reaction and the Molisch test. TLC was carried out on silica gel $G$ plates, with the underlayer solution of an eluent system composed of $\mathrm{CHCl}_{3}-$ methanol-water (10:7:2 by vol., $4^{\circ} \mathrm{C}$ ). The saponins were visualised by incubation with the vanillin-sulphuric acid reagent at $100^{\circ} \mathrm{C}$ for 10 min. GSP contained $90 \%$ saponins after recovery on a silica gel. The purified saponins were tested positive by the Liebermann-Burchard reaction and the Molisch test of steroidal saponin. GSP was dissolved in diluted alcohol for the cell culture experiments, and the final concentration of alcohol was less than 3:1000 (v/v).

\section{Cell culture}

Native PC12 cells (CRL-1721; ATCC, Rockville, MD, USA) were maintained in Dulbecco's modified Eagle's medium (Invitrogen, Carlsbad, CA, USA) supplemented with 5\% (v/v) fetal bovine serum (Hyclone, Logan, UT, USA), 10\% (v/v) horse serum (Invitrogen), 100 units/ml penicillin and $80 \mu \mathrm{g} / \mathrm{ml}$ gentamicin at $37^{\circ} \mathrm{C}$ in a humidified atmosphere with $5 \% \mathrm{CO}_{2}(\mathrm{v} / \mathrm{v})$. All experiments were carried out with subconfluent cells plated on poly-L-lysine-coated plates. To obtain neuron-like dPC12 cells, subconfluent cells were maintained in Dulbecco's modified Eagle's medium with $2 \%$ horse serum, $1 \%$ fetal bovine serum and NGF- $\beta$ (50 ng/ml) (Sigma-Aldrich, St Louis, MO, USA) for up to $8 \mathrm{~d}$.

\section{Hypoxia treatment}

dPC12 cells were pretreated with GSP and cultured in Dulbecco's modified Eagle's medium containing $0.5 \%$ horse serum and $0.5 \%$ fetal bovine serum without NGF in normoxia for $3 \mathrm{~h}$. The cells were then quickly placed into a multi-gas incubator $\left(2 \% \mathrm{O}_{2}(\mathrm{v} / \mathrm{v}), 5 \% \mathrm{CO}_{2}(\mathrm{v} / \mathrm{v})\right.$ and $93 \% \mathrm{~N}_{2}(\mathrm{v} / \mathrm{v})$; Nuaire, Plymouth, MN, USA), which maintains a precise $\mathrm{O}_{2}$ concentration $(1-21 \%)$ by injecting $\mathrm{N}_{2}$ and $\mathrm{CO}_{2}$ into the incubator.

\section{Cell viability}

Cell viability was determined using the 3-(4,5-dimethylthiazol-2-yl)-2,5-diphenyl tetrazolium bromide (MTT) reduction assay and lactate dehydrogenase (LDH) release assay. PC12 cells were plated on ninety-six-well plates in $100 \mu \mathrm{l} /$ well media containing NGF- $\beta$ at a density of $2 \times 10^{4}$ cells $/ \mathrm{ml}$ and maintained for $8 \mathrm{~d}$ in order to induce dPC12 cells.

3-(4,5-Dimethylthiazol-2-yl)-2,5-diphenyl tetrazolium bromide reduction assay. At the end of the hypoxia exposure, the cells were incubated with MTT $(0.5 \mathrm{mg} / \mathrm{ml})$ for $4 \mathrm{~h}$ at $37^{\circ} \mathrm{C}$. The supernatants were then carefully discarded, and $150 \mu$ l dimethyl sulphoxide (Sigma-Aldrich) was added to each well to dissolve the MTT formazan product from the metabolically active cells. The absorbance was measured by using a microplate reader (Bio-Rad, Hercules, CA, USA) at a test wavelength of $550 \mathrm{~nm}$ and a reference wavelength of $630 \mathrm{~nm}$.

Lactate dehydrogenase release assay. A colorimetric assay based on the measurement of LDH activity released from the cytosol of damaged cells into the supernatant was used to quantify cell death and cell lysis. The hypoxic, differentiated cells were cultured in Dulbecco's modified Eagle's medium containing 0.5\% horse serum and 0.5\% fetal bovine serum for the LDH assay ${ }^{(26,27)}$. At the end of 
the hypoxia exposure time, $100 \mu \mathrm{l}$ of the cell-free media were transferred into new wells, and LDH concentration was determined using the Cytotoxicity Detection Kit (LDH; Roche Applied Science, Basel, Switzerland). The percentage of cytotoxicity was calculated using the following equation: cytotoxicity $(\%)=($ experimental value - low control)/(high control - low control). Low control was the amount of spontaneously released $\mathrm{LDH}$, and high control was the amount of maximum releasable LDH. Absorbance was measured using a microplate reader (Bio-Rad) at a test wavelength of $490 \mathrm{~nm}$ and a reference wavelength of $630 \mathrm{~nm}$.

\section{Immunocytochemistry and immunoblot analyses}

Immunocytochemistry. To obtain dPC12 cells for immunocytochemistry, PC12 cells were seeded on a $10 \mathrm{~mm} \times 10 \mathrm{~mm}$ cover glass placed in a twenty-four-well plate at a concentration of $5 \times 10^{3}$ cells/well for $8 \mathrm{~d}$ and cultured in a serum-free medium. At the end of the culture time, the cells were fixed in $4 \%(\mathrm{w} / \mathrm{v})$ paraformaldehyde at room temperature for $15 \mathrm{~min}$, permeabilised with $0.3 \%$ $(\mathrm{v} / \mathrm{v})$ Triton $\mathrm{X}-100$ at $37^{\circ} \mathrm{C}$ for $15 \mathrm{~min}$ and blocked in $2 \%$ bovine serum albumin for $10 \mathrm{~min}$. Subsequently, the cells were incubated overnight with an anti-TUJ1 (neuronspecific class III $\beta$-tubulin) mAb (1:1000; Abcam, Cambridge, UK) in PBS containing $1 \%(\mathrm{v} / \mathrm{v})$ bovine serum albumin at $4^{\circ} \mathrm{C}$. Immunoreactivity was detected using tetramethyl rhodamine isothiocyanate-conjugated anti-mouse IgG (1:50) at room temperature for $30 \mathrm{~min}$. In addition, 4'-6-diamidino-2-phenylindole $(1 \mu \mathrm{g} / \mathrm{ml})$ was added for $5 \mathrm{~min}$ to stain the cell nucleus. The samples treated with the antibody dilution instead of the primary antibody were used as negative controls for anti-TUJ1 immunostaining. Fluorescence was visualised under a confocal laser scanning microscope (Leica TCS SP5, Wetzlar, Germany).

Immunoblot analyses. For immunoblots, the cells were washed with PBS and lysed with lysis buffer $(50 \mathrm{~mm}$-Tris, $150 \mathrm{~mm}-\mathrm{NaCl}, 1 \mathrm{~mm}$-EDTA, $50 \mathrm{~mm}-\mathrm{NaF}, 1 \mathrm{~mm}$-phenylmethylsulfonyl fluoride and $1 \%(\mathrm{v} / \mathrm{v})$ Triton X-100, $\mathrm{pH} 7 \cdot 5$ ) containing one tablet of the complete protease inhibitor cocktail (Roche Applied Science) per $10 \mathrm{ml}$ of the buffer. The extraction of nuclear and cytoplasmic protein was performed using an extraction kit (Beyotime Institute of Biotechnology, Shanghai, China) according to the manufacturer's instructions as described previously ${ }^{(28)}$. Protein concentration was determined using the Bradford assay. Proteins were separated by SDS-PAGE on a $12 \%$ acrylamide-bisacrylamide separation gel and 5\% acrylamide-bisacrylamide stacking gel, and electrotransferred onto nitrocellulose membranes. After blocking with $2 \%$ bovine serum albumin, the membranes were subjected to immunoblot analysis by incubating the membrane overnight at $4^{\circ} \mathrm{C}$ with the following primary antibodies: rat anti-TUJ1 monoclonal antibody (1:800; Abcam, Cambridge, UK); rabbit anti-CAT polyclonal antibody
(1:300; USCN Life Science \& Technology Company, Missouri, TX, USA); rabbit anti-p65 monoclonal antibody (1:800; Signalway Antibody Company Limited, Pearland, TX, USA); anti- $\beta$-actin monoclonal antibody (1:2000; ProMab Biotechnologies, Inc., Richmond, CA, USA). Peroxidase-conjugated AffiniPure rabbit anti-goat IgG $(\mathrm{H}+\mathrm{L})$ and peroxidase-conjugated AffiniPure goat antimouse $\operatorname{IgG}(\mathrm{H}+\mathrm{L})$ were used as the secondary antibodies (1:5000; ZSGB-BIO, Inc., Beijing, China). Protein bands were visualised by using enhanced chemiluminescence, as described previously ${ }^{(29)}$, using an enhanced chemiluminescence Western blot analysis system kit (Amersham Biosciences Corporation, Piscataway, NJ, USA). Image densitometric analyses of the immunoreactive protein bands were performed using Gel photodensitometry analysis software (Bio-Rad).

\section{Real-time $P C R$}

Total RNA extraction. Total RNA was isolated from PC12 cells by extraction with Trizol (Invitrogen) according to the manufacturer's instructions. The RNA samples were quantified by measuring $A_{260}$ on a spectrophotometer. The $A_{260}: A_{280}$ ratio ranged from 1.95 to $2 \cdot 0$, and the samples were checked for integrity on a formaldehyde agarose gel. Reverse transcription of $5 \mu \mathrm{g}$ RNA was performed with SuperScript III RT (Invitrogen) according to the manufacturer's instructions.

Quantitative real-time PCR of the catalase and p65 genes. Quantitative real-time PCR was performed using the SYBR Green Kit (Invitrogen) on a Bio-Rad IQ5 (BioRad). The PCR mixtures contained $25 \mathrm{ng}$ complementary DNA, $0 \cdot 2 \mu \mathrm{mol} / 1$ of each specific primer and the SYBR Green reaction mix (Invitrogen). The mixtures were incubated at $95^{\circ} \mathrm{C}$ for $2 \mathrm{~s}$, and then forty cycles at $95^{\circ} \mathrm{C}$ for $10 \mathrm{~min}, 60^{\circ} \mathrm{C}$ for $20 \mathrm{~min}$ and $72^{\circ} \mathrm{C}$ for $45 \mathrm{~min}$ were conducted. This step was followed by a melting curve analysis performed between 72 and $95^{\circ} \mathrm{C}$, holding $45 \mathrm{~s}$ on the first step and $5 \mathrm{~s}$ on the next steps. The primers used were as follows: CAT forward, 5'-AAC AGC TTC AGC GCA CCA GA-3'; CAT reverse, 5'-TTC AGG TGG TTG GCA ATG TTC-3'; p65 forward, 5'-GCC TTG CTT GGC AAC AAC AC-3'; p65 reverse, 5'-ATC CTG TCA CCA GGC GAG TT-3'; $\beta$-actin forward, $5^{\prime}$-AGT GTG ACG TTG ACA TCC GTA- $3^{\prime}$; $\beta$-actin reverse, 5'-GCC AGA GCA GTA ATC TCC TTC T- 3 '. Independent real-time PCR experiments were performed using the same complementary DNA for both the target gene and reference gene. At the end of the PCR, the amplified product was resolved on a $2 \%$ agarose gel to determine whether a single product was amplified. Data were analysed using Bio-Rad IQ5 operating software to determine the threshold cycle $\left(C_{\mathrm{T}}\right)$ above the background for each reaction. The relative transcript amount of the target gene was normalised to that of $\beta$-actin using the $2^{-\Delta \Delta C_{\mathrm{T}}}$ method based on a previous study ${ }^{(30)}$. 


\section{Malondialdehyde content determination}

Cells were collected after being exposed to hypoxia for $24 \mathrm{~h}$. The cells were carefully rinsed with cold PBS and homogenised with cold $0 \cdot 86 \%$ isotonic NaCl. MDA content was then determined according to the method described previously ${ }^{(31,32)}$ and according to the manufacturer's instructions (Nanjing Jiancheng Company, Nanjing, China).

\section{8-Hydroxy-deoxyguanosine ELISA assay}

Cells were pretreated with GSP $(10 \mathrm{ng} / \mathrm{ml})$, exposed to hypoxia for $24 \mathrm{~h}$, and then the supernatant was immediately collected for an ELISA. The supernatant was centrifuged $(1000 \mathrm{~g})$ for $20 \mathrm{~min}$ to remove particulates before the assay was performed. The concentration of 8-hydroxy-deoxyguanosine in the samples was determined using the ELISA method ${ }^{(33)}$ according to the instructions from the ELISA kit (USCN Life Science \& Technology Company).

\section{Antioxidant activity determination}

For the antioxidant assay, the cells were treated with the same conditions as those used in the MDA assay. CAT activity was determined with UV spectrophotometry according to the instructions from the assay kit (Nanjing Jiancheng Company) ${ }^{(34)}$. Protein content was then determined using the Bradford assay.

\section{Statistical analysis}

Data are presented as means with their standard errors. ANOVA followed by Fisher's least significant difference test or Dunnett's multiple comparison test was used to assess differences between groups. A $P$ value less than 0.05 was considered to be statistically significant. The relative changes of mRNA levels are presented as percentages of the control samples and assumed to be $100 \%$.

\section{Results}

Garlic saponins protect cell viability and decrease the lactate dehydrogenase release rate of hypoxic differentiated PC12 cells

When dPC12 cells were cultured under hypoxic conditions for $36 \mathrm{~h}$, a decrease in cell viability was observed. However, cells treated with GSP under hypoxic conditions showed an increase in cell viability by $51.5,80.8$ and $53.6 \%$ when the cells were treated with $5 \times 10^{-2}, 0.5$ and $5 \mathrm{ng} / \mathrm{ml}$ of GSP, respectively, compared with the control. The $0.5 \mathrm{ng} / \mathrm{ml}$ dose of GSP was found to be most effective
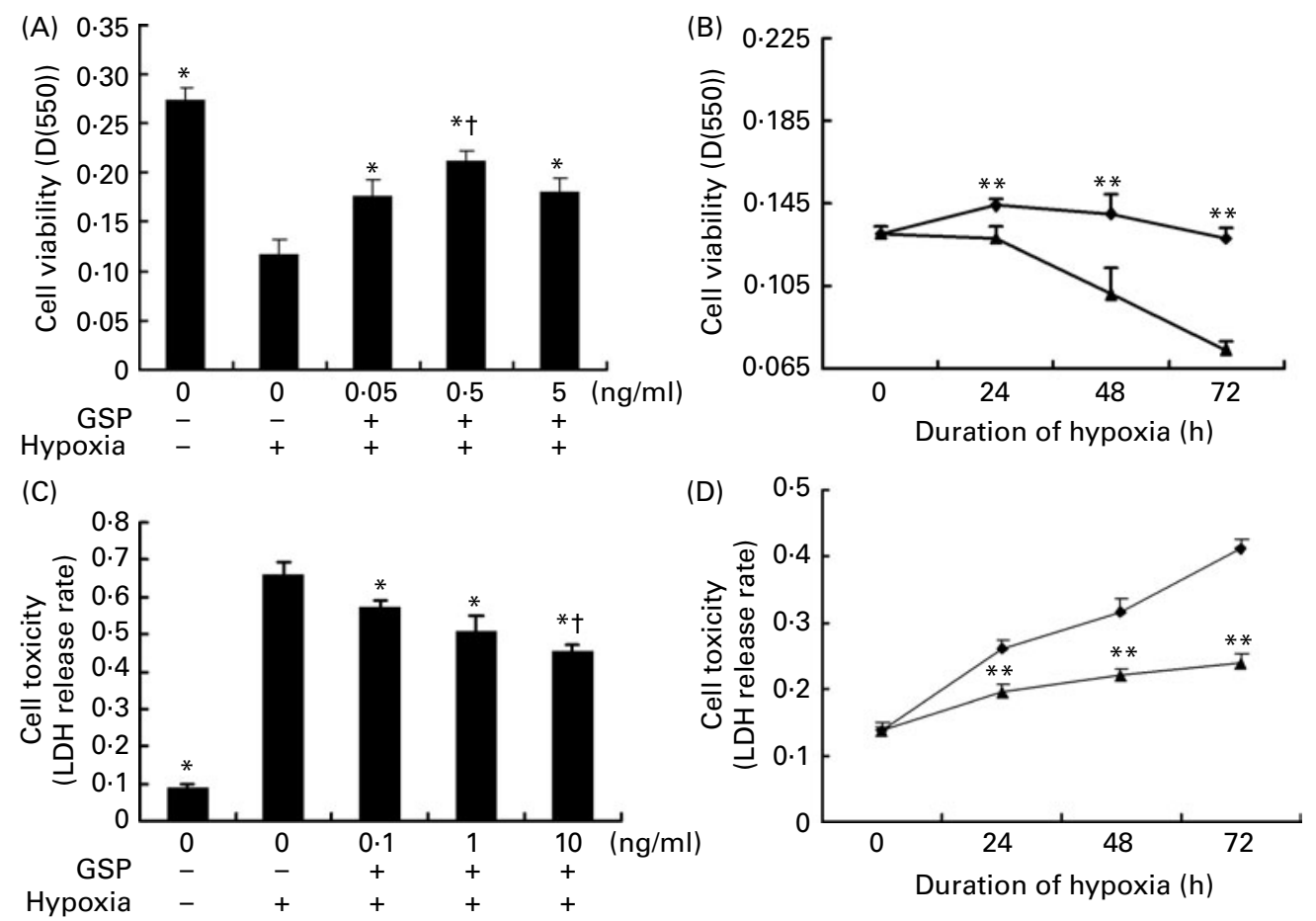

Fig. 1. Protective effects of garlic saponins (GSP) on hypoxia-induced toxicity in differentiated PC12 cells. Cells treated with GSP were incubated in normoxia for $3 \mathrm{~h}$ before exposure to hypoxia. Cell viability was assessed by measuring 3-(4,5-dimethylthiazol-2-yl)-2,5-diphenyl tetrazolium bromide reduction ((A) and (B)). Cell toxicity was assessed by the lactate dehydrogenase $(\mathrm{LDH})$ release rate $((\mathrm{C})$ and $(\mathrm{D}))$. (A) The viability of cells treated with $5 \times 10^{-2}-5 \mathrm{ng} / \mathrm{ml} \mathrm{GSP}$ with $36 \mathrm{~h}$ of hypoxic exposure. (B) The viability of cells incubated in hypoxia for $0,24,48$ or $72 \mathrm{~h}$. (C) LDH release rate of cells treated with $0.1-10 \mathrm{ng} / \mathrm{ml}$ GSP with $48 \mathrm{~h}$ of hypoxic exposure. (D) LDH release rate of cells incubated in hypoxia for $0,24,48$ or $72 \mathrm{~h}$. Values are means, with their standard errors represented by vertical bars $(n 5) ;{ }^{*} P<0.01 \mathrm{v}$. hypoxia control; $\dagger P<0.05 \mathrm{v}$. the other GSP groups. ${ }^{\star \star} P<0.05 \mathrm{v}$. the control at the same time point. (B) $\longrightarrow$ - GSP (10 ng/ml); $\longrightarrow-$ control; (D) $\longrightarrow$, control; $\longrightarrow$, GSP $(10 \mathrm{ng} / \mathrm{ml})$. 
at increasing cell viability (Fig. 1(A)). The hypoxic dPC12 cells showed decreasing cell viability at 24,48 and $72 \mathrm{~h}$, while the cells treated with GSP showed an increase in the rate of cell viability of $12.5,38.6$ and $73 \%$, respectively, compared with the control (Fig. 1(B)).

Treatment with GSP $(0 \cdot 1-10 \mathrm{ng} / \mathrm{ml})$ attenuated $\mathrm{LDH}$ leakage of hypoxic dPC12 cells, which was increased by hypoxia due to cell damage (Fig. 1(C)). Moreover, the LDH release rate of cells treated with GSP decreased $25 \cdot 4,30 \cdot 6$ and $41.6 \%$ at 24, 48 and $72 \mathrm{~h}$, respectively, compared with the control (Fig. 1(D)).

Hypoxia caused dramatic changes in the neuronal morphology of dPC12 cells, and many of them lost the characteristic irregular shape with neurite outgrowth and acquired a round appearance with shorter neurites that were reduced or absent. However, cells treated with GSP maintained a differentiated state and had longer neurites compared with the hypoxic control (Fig. 2(A) and (B)). Moreover, the expression of TUJ1, a neuronal marker protein, was increased in cells treated with GSP compared with the hypoxic control (Fig. 2(C)).

\section{Garlic saponins protect differentiated PC12 cells from oxidative damage induced by hypoxia}

Hypoxia treatment for $24 \mathrm{~h}$ induced oxidative damage of NGF-deprived dPC12 cells. We observed an increase in intracellular MDA and 8-hydroxy-deoxyguanosine concentrations in the medium due to hypoxia. However, the production of MDA and 8-hydroxy-deoxyguanosine was significantly attenuated by treatment with GSP $(P<0 \cdot 01$; Fig. 3). Moreover, the activity and abundance of CAT in
(A) (a)
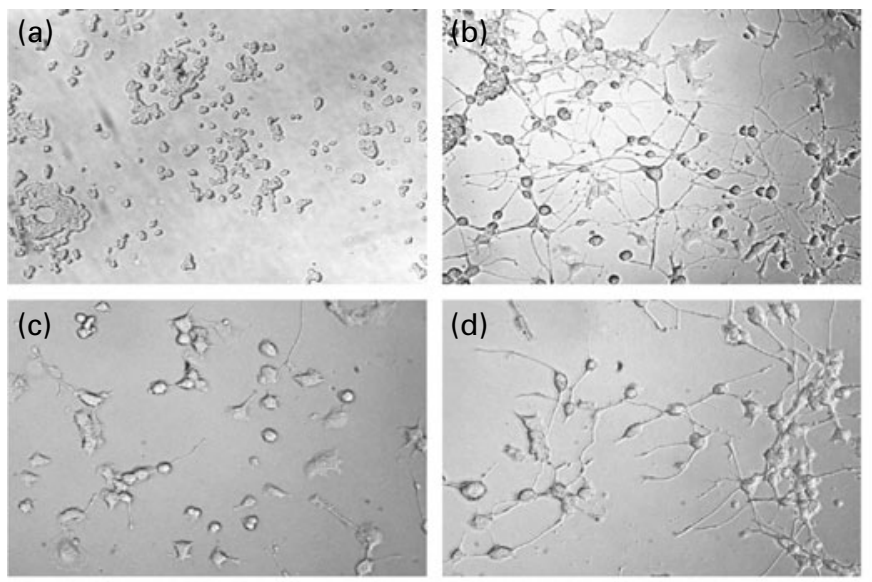

(B)
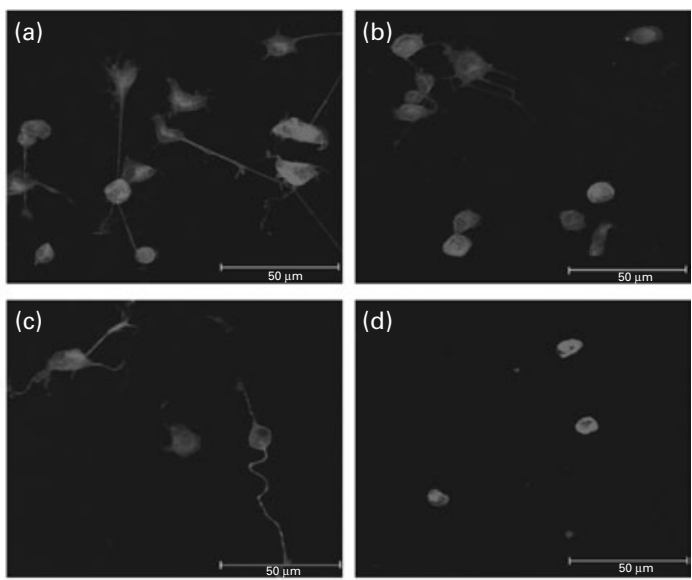

(C)
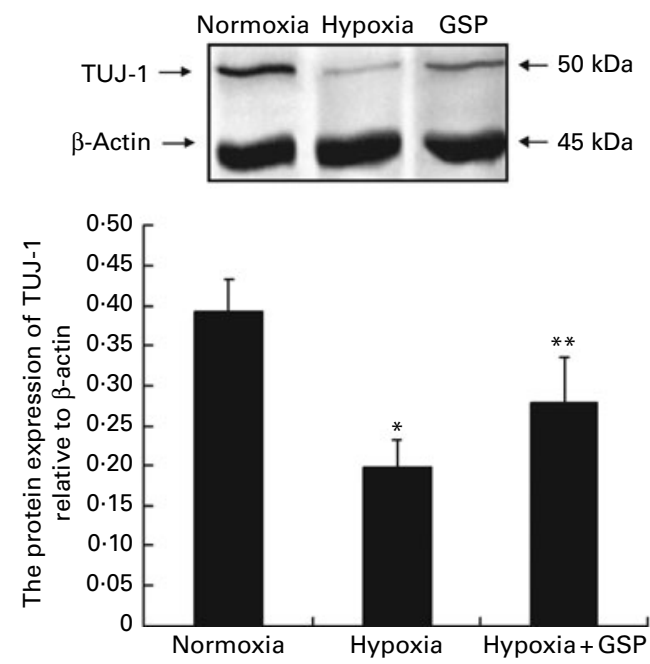

Fig. 2. Effects of garlic saponins (GSP) on the neuronal morphology of hypoxic differentiated PC12 (dPC12) cells. A number of hypoxic cells tended to lose their characteristic shape, acquiring a round appearance and showing shorter, few or even no neurites. However, hypoxic cells treated with GSP maintained the number and length of the neurites. (A) PC12 cell photomicrographs using an Olympus microscope (10 × 32). (a) Native PC12 cells, (b) dPC12 cells, (c) dPC12 cells with $36 \mathrm{~h}$ of hypoxic exposure, (d) dPC12 cells treated with GSP (10 ng/ml) and $36 \mathrm{~h}$ of hypoxic exposure. (B) Immunofluorescence of neuron-specific class III $\beta$-tubulin (TUJ1) in cells using a confocal laser scanning microscope. Cells were stained with an anti-TUJ1 antibody (red fluorescence) for TUJ1 localisation and 4'-6-diamidino-2-phenylindole (blue fluorescence) for nuclear visualisation. The neuronal morphology of hypoxic dPC12 cells was protected, and the expression of TUJ1 was up-regulated by GSP. (a) dPC12 cells treated with GSP (10 ng/ml, $24 \mathrm{~h}$ hypoxia), (b) dPC12 cells ( $24 \mathrm{~h}$ hypoxia), (c) dPC12 cells treated with GSP (10 ng/ml, $72 \mathrm{~h}$ hypoxia), (d) dPC12 cells (72h hypoxia). (C) Detection of TUJ1 protein by Western blotting with cell lysate from dPC12 cells under hypoxic conditions for $24 \mathrm{~h}$. Values are means, with their standard errors represented by vertical bars $(n 4)$. ${ }^{\star} P<0.01 v$. normoxia; ${ }^{\star \star} P<0.05 v$. normoxia and hypoxia, respectively. 

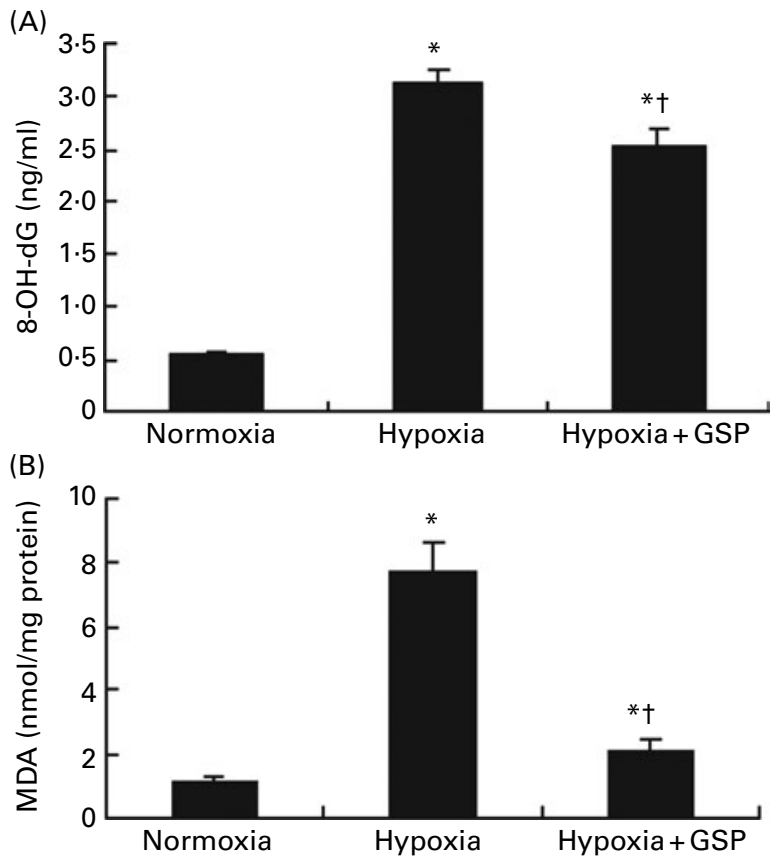

Fig. 3. Protective effects of garlic saponins (GSP, $10 \mathrm{ng} / \mathrm{ml}$ ) on the oxidative damage of differentiated PC12 cells induced by hypoxia $(24 \mathrm{~h})$. (A) Malondialdehyde (MDA) content and (B) 8-hydroxy-deoxyguanosine (8-OH-dG) content. Values are means, with their standard errors represented by vertical bars $(n 5)$. ${ }^{*} P<0.05 \mathrm{v}$. normoxia; $† P<0.01 \mathrm{v}$. hypoxia.

GSP-treated cells were significantly higher than in the corresponding control $(P<0 \cdot 01 ;$ Fig. 4). The CAT activity in GSP-treated cells was 5.5 times higher than in the hypoxic control cells. Moreover, treatment with GSP up-regulated the mRNA and protein expression of CAT, which was significantly decreased in the hypoxic control cells $(P<0 \cdot 05$; Fig. 4). After exposure to hypoxia for $24 \mathrm{~h}$, the total protein expression of p65 in GSP-treated cells was lower than that in the hypoxic control cells. Moreover, the protein expression of nuclear p65 was also decreased (Fig. 5). GSP had no significant effect on the mRNA expression of p65 in dPC12 cells ( $P>0.05$; data not shown).

\section{Discussion}

Hypoxia can cause cell injury and dysfunction ${ }^{(1)}$, which are in part due to the fact that oxidative stress affects the structure and function of proteins ${ }^{(13)}$, nucleic acids ${ }^{(14)}$ and lipids ${ }^{(15,17,18)}$. dPC12 cells exposed to $2 \% \mathrm{O}_{2}$ for $24-72 \mathrm{~h}$ were dramatically damaged and showed a significant decrease in cell number and viability. In the present study, we demonstrated that GSP had a protective effect against cell injury and death caused by hypoxia. Using MTT and LDH assays, we demonstrated that GSP protected cell viability under hypoxic conditions. In addition, hypoxia has been shown to decrease the expression of neuronal marker genes in PC12 cells ${ }^{(35)}$. Here, we also found that $2 \% \mathrm{O}_{2}$ decreased the protein expression of the neuronal cell marker TUJ1; however, GSP attenuated this decrease.
These results indicated that GSP has protective effects against hypoxia-induced damage of dPC12 cells.

Excessive ROS induced by hypoxia are extremely reactive and can cause molecular oxidative damage and subsequent cell death. MDA, an oxidative degradation product of cell membrane lipids, is generally considered as an indicator of lipid peroxidation ${ }^{(36-38)}$. The oxidised

(B)
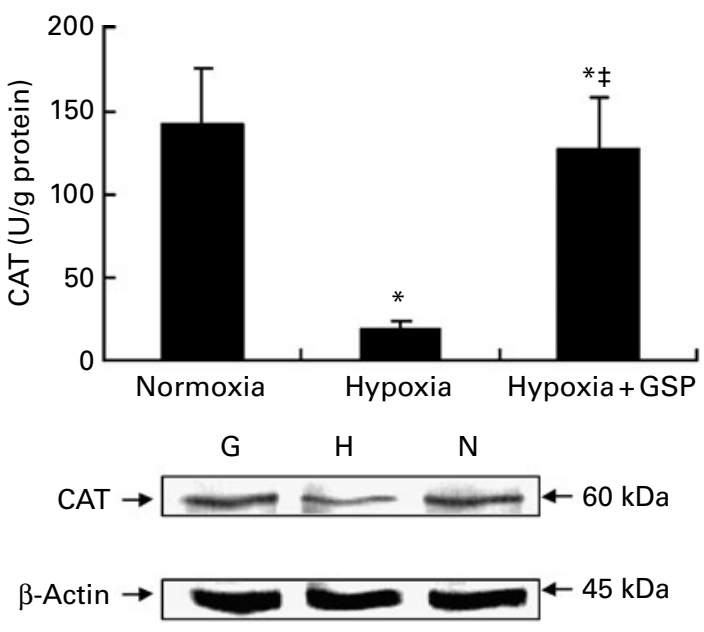

(C)

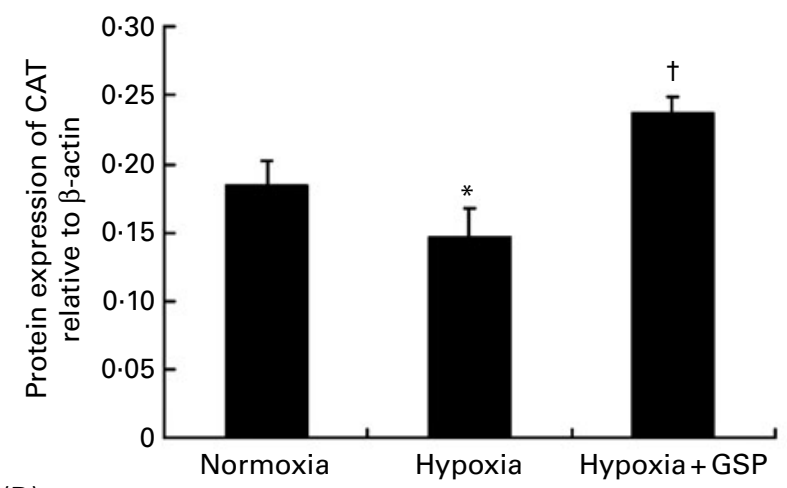

(D)

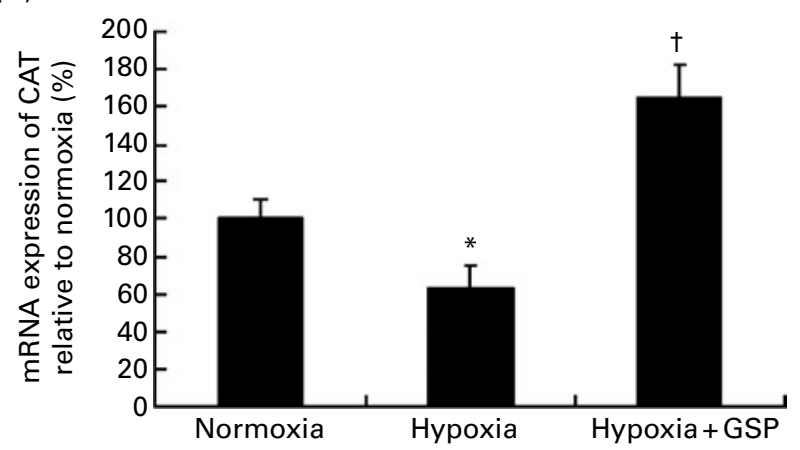

Fig. 4. Garlic saponins (GSP, $10 \mathrm{ng} / \mathrm{ml}$ ) up-regulate the expression and activity of catalase (CAT) in hypoxic differentiated PC12 cells (24 h hypoxia). Hypoxia decreased the expression and activity of CAT, but GSP treatment markedly ameliorated this effect. (A) CAT activity. (B) Detection of CAT protein by Western blot. (C) The mRNA expression of CAT analysed by real-time RT-PCR. $2^{-\Delta \Delta C_{T}}$ was calculated to represent the relative value of mRNA, and normoxia was used as the control and assumed to be $100 \%$. Values are means, with their standard errors represented by vertical bars (n 4). ${ }^{\star} P<0.05 v$. normoxia; $\dagger P<0.01 v$. normoxia or hypoxia; $\ddagger P<0.01$ $v$. hypoxia. 


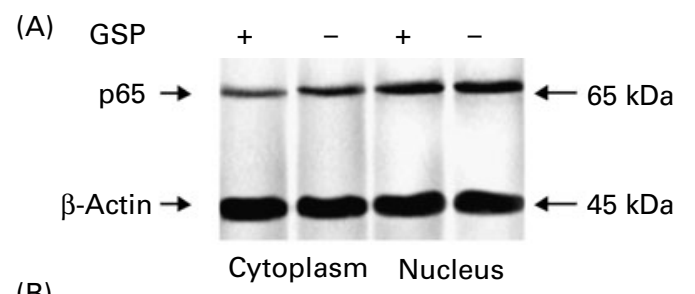

(B)

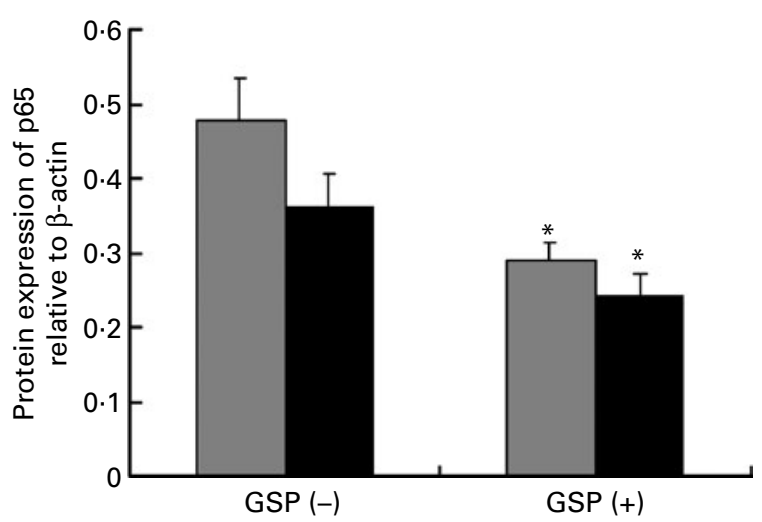

Fig. 5. Garlic saponins (GSP) down-regulate the total and nuclear expression of p65 in hypoxic differentiated PC12 (dPC12) cells. dPC12 cells were pretreated with GSP $(10 \mathrm{ng} / \mathrm{ml})$ and exposed to hypoxia for $24 \mathrm{~h}$. (A) Detection of p65 by Western blot. Nuclear and cytoplasmic proteins were extracted from cells after exposure to hypoxia for $24 \mathrm{~h}$. (B) Protein expression of p65 relative to $\beta$-actin. The total expression of $p 65$ in hypoxic cells was significantly decreased by GSP, and the expression of nuclear p65 decreased. Values are means with their standard errors represented by vertical bars $(n 4) .{ }^{*} P<0.01$ $v$. the corresponding GSP $(-)$ group. $\square$, Cytoplasm; $\square$, nucleus.

nucleoside 8-OHdG is a frequently detected and extensively studied factor of oxidative DNA damage, since it is the major oxidative lesion that occurs in nuclear and mitochondria DNA and can be detected by a variety of assays $^{(39-42)}$. In the present study, the production of MDA, LDH leakage and 8-hydroxy-deoxyguanosine was significantly decreased by pretreatment with GSP before hypoxic exposure. These results indicated that the oxidative damage of membrane lipids, membrane structure and DNA of hypoxic cells was inhibited by GSP treatment.

In the present study, we investigated the activity and expression of CAT in $\mathrm{dPC} 12$ cells. CAT activity in $\mathrm{dPC} 12$ cells decreased due to hypoxia-induced oxidative stress. We demonstrated that treatment with GSP significantly increased the activity and expression of CAT in hypoxic cells. It is known that CAT may decompose toxic $\mathrm{H}_{2} \mathrm{O}_{2}$, which not only oxidises proteins, nucleic acids and lipids, but also modulates several proteins including the NF-кB p65 signalling pathway. Antioxidant enzymes provide important protective mechanisms against oxidative damage. CAT is one of the most active catalysts produced in nature. At high substrate concentrations, CAT decomposes toxic $\mathrm{H}_{2} \mathrm{O}_{2}$ at an extremely rapid rate in a catalytic reaction, whereby $\mathrm{H}_{2} \mathrm{O}_{2}$ acts as both an acceptor and donor of hydrogen molecules in the equation $2 \mathrm{H}_{2} \mathrm{O}_{2} \rightarrow$ $2 \mathrm{H}_{2} \mathrm{O}+\mathrm{O}_{2}$. Moreover, CAT is unique among $\mathrm{H}_{2} \mathrm{O}_{2}$ scavenger enzymes, in that it degrades $\mathrm{H}_{2} \mathrm{O}_{2}$ without consuming cellular reducing equivalents. It has been proposed that CAT may be uniquely suited to regulate the homeostasis of $\mathrm{H}_{2} \mathrm{O}_{2}$ in the cell.

It has been previously shown that oxidants can induce $\mathrm{NF}-\kappa \mathrm{B}$ activation and concomitantly increase the translocation of p65 to the nucleus in PC12 cells, where intracellular ROS accumulates and oxidative damage subsequently occurs ${ }^{(43)}$. ROS, primarily $\mathrm{H}_{2} \mathrm{O}_{2}$, can alter the protein redox status and modulate several signalling pathways. $\mathrm{H}_{2} \mathrm{O}_{2}$ activates p38MAPK and other MAPK, such as extracellular signal-regulated kinase $1 / 2$, which activates transcription factors including NF- $\mathrm{BB}$. The present study showed that hypoxia can activate NF- $\mathrm{B}$ and increase its nuclear translocation in PC12 cells, which is consistent with previous findings in other cell types ${ }^{(44-48)}$. Moreover, p38 or extracellular signal-regulated kinase 1/2 MAPK was activated in hypoxic PC12 or other cell types ${ }^{(49,50)}$. Therefore, ROS may be an important signalling pathway for NF- $\mathrm{KB}$ activation in hypoxic PC12 cells. Recently, Oliver et al. ${ }^{(51)}$ has shown that both continuous and intermittent hypoxia activate NF- $\mathrm{BB}$ through the p65 signalling pathway, rather than through the non-canonical pathway. On the other hand, pretreatment with classical antioxidants has been shown to prevent the $\mathrm{H}_{2} \mathrm{O}_{2}$-induced activation of $\mathrm{MAPK}^{(52-54)}$. Overexpression of the CAT gene also causes a decrease in intracellular $\mathrm{H}_{2} \mathrm{O}_{2}$ levels and downregulates $\mathrm{NF}-\kappa \mathrm{B}$ activation ${ }^{(55)}$. In the present study, we also found that the total and nuclear expression of NF-кB p65 in hypoxic cells was decreased by the treatment with GSP. NF-кB is composed of five homo- and heterodimers of proteins containing a Rel homology domain in mammalian cells. p65 (RelA), one of the predominant NF-кB isoforms, has a transactivation domain at the C-terminus. Since p65 is responsible for the transcriptional activity of $\mathrm{NF}-\kappa \mathrm{B}$, it has been extensively studied. In unstimulated cells, the NF- $\mathrm{B}$ dimers are sequestered in the cytoplasm by $I \kappa \mathrm{B}^{(56)}$. When I $\mathrm{B}$ becomes phosphorylated, NF- $\mathrm{B}$ is activated and the p65 subunit is then free to enter the nucleus, where it acts as a transcription factor and regulates the expression of specific genes. In mammalian systems, $\mathrm{NF}-\kappa \mathrm{B}$ is not only involved in the regulation of the oxidative stress response, but also plays a central role in regulating normal cellular growth and metabolism. Moreover, NF- $\mathrm{kB}$ activation can lead to apoptosis or necrosis of cells under oxidative stress conditions.

In addition, the hydroxylases that confer oxygen sensitivity to the hypoxia-inducible factor pathway may also play a role in oxygen sensing in the NF- $\mathrm{B}$ pathway. Prolyl hydroxylases appear to repress the p65 pathway through mechanisms that may include the direct hydroxylation of I $\mathrm{B}$ kinase $\beta^{(57)}$. Furthermore, the asparaginyl hydroxylase factor inhibiting the hypoxia-inducible factor has been shown to hydroxylate $\mathrm{I} \kappa \mathrm{B} \alpha{ }^{(58)}$. Hydroxylase activity is attenuated by an increase in ROS, which is generated during the hypoxic stress response. Therefore, we hypothesise that a decrease in the inhibition of 
hydroxylase activity induced by hypoxia may be another mechanism for the GSP-mediated effects on the p65 signalling pathway.

The expression of most antioxidant enzymes, including CAT, is tightly controlled by the antioxidant response element (ARE) and is activated by nuclear factor E2-related factor $2(\mathrm{Nrf} 2)^{(59)}$. ARE is present in the promoter region of mammalian glutathione $S$-transferase, metallothionein-I, MnSod and CAT genes, and causes the induction of these genes in response to oxidants. Nrf2 is the transcription factor that binds to the ARE. The protective effects of Nrf2 activation in reducing oxidative stress in both in vitro and in vivo models of neuron damage have been described in several studies ${ }^{(59)}$. Other studies have reported that the oxidative damage induced by $\mathrm{H}_{2} \mathrm{O}_{2}$ or mitochondrial toxins can be protected by Nrf2/ARE activation in PC12 cells $^{(60,61)}$. Therefore, we hypothesise that Nrf2/ARE activation may be an important pathway for the induction of CAT expression that is induced by GSP treatment. GSP may not only act as an antioxidant for the direct elimination of ROS, but also may act as a signalling molecule for the activation of Nrf2/ARE. Further study will be needed to explore the mechanisms of the protective effects of GSP in hypoxic dPC12 cells.

The present study suggests that GSP may act as an antioxidant to protect $\mathrm{dPC} 12$ cells from the direct damage of hypoxia-induced ROS or may mediate protective effects through redox-sensitive signalling pathways mediated by ROS. Moreover, the GSP-mediated increase in CAT activity, which may act by decreasing the production of ROS or indirectly regulating the expression of $\mathrm{p} 65$, may be an important mechanism for the protective effects of GSP on hypoxic dPC12 cells. In conclusion, GSP can protect dPC12 cells against hypoxia through an antioxidant effect, which is in part due to an up-regulation of the activity and expression of CAT and a decrease in the expression and nuclear distribution of p65.

\section{Acknowledgements}

We are grateful to You-Ming Fan for the kind gift of PC12 cells. The present study was supported by the 973 project of China (no. 2006cb504101). There are no conflicts of interest. H. L. and Y.-Q. G. designed the research; H. L. and J. H. conducted the study; H. L., W.-G. L., and Q.-Y. H. performed the statistical analysis; H. L., J. H., W.-G. L., and Y.-Q. G. wrote the manuscript; Y.-Q. G. had the primary responsibility for the final content.

\section{References}

1. Clanton TL (2007) Hypoxia-induced reactive oxygen species formation in skeletal muscle. J Appl Physiol 2, 2379-2388.

2. Lin $\mathrm{YH}$, Liu AH, Pan $\mathrm{Y}$, et al. (2007) Reduction in the in vitro expression of Brain-Pancreas Relative Protein by oxygen and glucose-deprivation. Mol Cell Biochem 295, 199-204.
3. Yamada J, Yoshimura S, Yamakawa H, et al. (2003) Cell permeable ROS scavengers, Tiron and Tempol, rescue PC12 cell death caused by pyrogallol or hypoxia/reoxygenation. Neurosci Res 45, 1-8.

4. Wang G, Hazra TK, Mitra S, et al. (2000) Mitochondrial DNA damage and a hypoxic response are induced by $\mathrm{CoCl}(2)$ in rat neuronal PC12 cells. Nucleic Acids Res 28, 2135-2140.

5. Willett WC (1999) Goals for nutrition in the year 2000. $C A$ Cancer J Clin 49, 331-352.

6. Matsuura H (2001) Saponins in garlic as modifiers of the risk of cardiovascular disease. J Nutr 131, 1000S-1005S.

7. Durak I, Kavutcu M, Aytaç B, et al. (2004) Effects of garlic extract consumption on blood lipid and oxidant/antioxidant parameters in humans with high blood cholesterol. J Nutr Biochem 15, 373-377.

8. Lacaille-Dubois MA \& Wagner H (1996) A review of the biological and pharmacological activities of saponins. Phytomedicine 2, 363-386.

9. Pedraza-Chaverri J, Yam-Canul P, Chirino YI, et al. (2008) Protective effects of garlic powder against potassium dichromate-induced oxidative stress and nephrotoxicity. Food Chem Toxicol 46, 619-627.

10. Gedik N, Kabasakal L, Sehirli O, et al. (2005) Long-term administration of aqueous garlic extract (AGE) alleviates liver fibrosis and oxidative damage induced by biliary obstruction in rats. Life Sci 76, 2593-2606.

11. Sangeetha T \& Quine SD (2006) Antilipoperoxidative and antioxidant effects of $S$-allyl cysteine sulfoxide on isoproterenol-induced myocar-dial infarction in Wistar rats. J Biochem Mol Toxicol 20, 167-173.

12. Helen A, Krishnakumar K, Vijayammal PL, et al. (2003) A comparative study of antioxidants $S$-allyl cysteine sulfoxide and vitamin $\mathrm{E}$ on the damages induced by nicotine in rats. Pharmacology 67, 113-117.

13. González G, Celedón G, Sandoval M, et al. (2002) Hypobaric hypoxia-reoxygenation diminishes band 3 protein functions in human erythrocytes. Pflugers Arch 445, 337-341.

14. Hartman P, Ponder R, Lo HH, et al. (2004) Mitochondrial oxidative stress can lead to nuclear hypermutability. Mech Ageing Dev 125, 417-420.

15. González G, Celedón G, Escobar M, et al. (2005) Red cell membrane lipid changes at $3500 \mathrm{~m}$ and on return to sea level. High Alt Med Biol 125, 320-326.

16. Davison GW, George L, Jackson SK, et al. (2002) Exercise, free radicals, and lipid peroxidation in type 1 diabetes mellitus. Free Radic Biol Med 33, 1543-1551.

17. Bailey DM, Davies B, Young IS, et al. (2003) EPR spectroscopic detection of free radical outflow from an isolated muscle bed in exercising humans. J Appl Physiol 94, $1714-1718$.

18. Jefferson JA, Simoni J, Escudero E, et al. (2004) Increased oxidative stress following acute and chronic high altitude exposure. High Alt Med Biol 5, 61-69.

19. Halliwell B \& Gutteridge JMC (2001) Free Radicals in Biology and Medicine. Oxford: Oxford University Press, pp. 936.

20. Rideout KE, Larsen D, Sulzer, et al. (2001) Proteasomal inhibition leads to formation of ubiquitim/alpha-sinuclein immureactive inclusions in PC12 cells. J Neurochem $\mathbf{7 8}$ 899-908.

21. Hartley A, Stone JM, Heron C, et al. (1994) Complex I inhibitors induce dose-dependent apoptosis in PC12 cells: relevance to Parkinson's disease. J Neurochem 63, 1987-1990.

22. Lipman T, Tabakman R \& Lazarovici P (2006) Neuroprotective effects of the stable nitroxide compound Tempol on 1-methyl-4-phenylpyridinium ion-induced neurotoxicity in the Nerve Growth Factor-differentiated model of pheochromocytoma PC12 cells. Eur J Pharmacol 549, 50-57. 
23. Tabakman R, Lazarovici P \& Kohen R (2002) Neuroprotective effects of carnosine and homocarnosine on pheochromocytoma PC12 cells exposed to ischemia. J Neurosci 68, 463-469.

24. Kotake-Nara E \& Saida K (2007) Characterization of $\mathrm{CoCl}_{2-}$ induced reactive oxygen species (ROS): inductions of neurite outgrowth and endothelin-2/vasoactive intestinal contractor in PC12 cells by $\mathrm{CoCl}_{2}$ are ROS dependent, but those by $\mathrm{MnCl}_{2}$ are not. Neurosci Lett 422, 223-227.

25. Peng JP, Chen H, Qiao YQ, et al. (1996) Two new steroidal saponins from allium sativum and their inhibitory effects on blood coagulability. Acta Pharmaceutica Sinica 31, 607-612.

26. Murphy EJ, Roberts E \& Horrocks LA (1993) Aluminum silicate toxicity in cell cultures. Neuroscience 55, 597-605.

27. Thomas JP, Geiger PG \& Girotti AW (1993) Lethal damage to endothelial cells by oxidized low density lipoprotein: role of selenoperoxidases in cytoprotection against lipid hydroperoxide- and iron-mediated reactions. J Lipid Res 34, 479-490.

28. Liu HT, Du YG, He JL, et al. (2010) Tetramethylpyrazine inhibits production of nitric oxide and inducible nitric oxide synthase in lipopolysaccharide-induced N9 microglial cells through blockade of MAPK and PI3K/Akt signaling pathways, and suppression of intracellular reactive oxygen species. J Ethnopharmacol 129, 335-343.

29. Kaushal GP, Kaushal V, Hong X, et al. (2001) Role and regulation of activation of caspases in cisplatin-induced injury to renal tubular epithelial cells. Kidney Int 60, 1726-1736.

30. Pfaffl MW (2001) A new mathematical model for relative quantification in real-time RT-PCR. Nucleic Acids Res 29, e45.

31. Zhang YM (2005) Protective effect of quercetin on aroclor 1254-induced oxidative damage in cultured chicken spermatogonial cells. Toxicol Sci 88, 545-550.

32. Ohkawa H, Ohishi N \& Yagi K (1979) Assay of lipid peroxides in animal tissues by thiobarbituric acid reaction. Anal Biochem 95, 351-358.

33. Song MF, Li YS, Ootsuyama Y, et al. (2009) Urea, the most abundant component in urine, cross-reacts with a commercial 8-OH-dG ELISA kit and contributes to overestimation of urinary 8-OH-dG. Free Radic Biol Med 47, 41-46.

34. Wang D, Wang L-J \& Zhu F-X (2008) In vitro and in vivo studies on the antioxidant activities of the aqueous extracts of Douchi (a traditional Chinese salt-fermented soybean food). Food Chem 107, 1421-1428.

35. Naranjo-Suárez S, Castellanos MC, Alvarez-Tejado $\mathrm{M}$, et al. (2003) Downregulation of hypoxia inducible factor-2 in PC12 cells by nerve growth factor stimulation. $J$ Biol Chem 278, 31895-31901.

36. Marnett LJ (2002) Oxy radicals, lipid peroxidation and DNA damage. Toxicology 181-182, 219-222.

37. Pialoux V, Brugniaux JV, Rock E, et al. (2010) Antioxidant status of elite athletes remains impaired 2 weeks after a simulated altitude training camp. Eur J Nutr 49, 285-292.

38. Matchett GA, Fathali N \& Hasegawa Y (2009) Hydrogen gas is ineffective in moderate and severe neonatal hypoxiaischemia rat models. Brain Res 1259, 90-97.

39. Hamilton ML, Guo Z, Fuller CD, et al. (2001) A reliable assessment of 8-oxo-2-deoxyguanosine levels in nuclear and mitochondrial DNA using the sodium iodide method to isolate DNA. Nucleic Acids Res 29, 2117-2126.

40. Lunec J, Holloway KA, Cooke MS, et al. (2002) Urinary 8-oxo-2-deoxyguanosine: redox regulation of DNA repair in vivo? Free Radic Biol Med 33, 875-885.

41. Dizdaroglu M (1992) Oxidative damage to DNA in mammalian chromatin. Mutat Res 275, 331-342.

42. Helbock HJ, Beckman KB \& Ames BN (1999) 8-Hydroxydeoxyguanosine and 8-hydroxyguanine as biomarkers of oxidative DNA damage. Methods Enzymol 300, 156-166.
43. France-Lanord V, Brugg B, Michel PP, et al. (1997) Mitochondrial free radical signal in ceramide-dependent apoptosis: a putative mechanism for neuronal death in Parkinson's disease. J Neurochem 69, 1612-1621.

44. Chandel NS, Trzyna WC, McClintock DS, et al. (2000) Role of oxidants in NF-kappa B activation and TNF-alpha gene transcription induced by hypoxia and endotoxin. J Immunol $\mathbf{6 5}$, 1013-1021.

45. Leeper-Woodford SK \& Detmer K (1999) Acute hypoxia increases alveolar macrophage tumor necrosis factor activity and alters NF-kappaB expression. Am JPhysiol 276, L909-L916.

46. Koong AC, Chen EY \& Giaccia AJ (1994) Hypoxia causes the activation of nuclear factor kappa B through the phosphorylation of I kappa B alpha on tyrosine residues. Cancer Res 54, $1425-1430$.

47. Matsui H, Ihara Y, Fujio Y, et al. (1999) Induction of interleukin (IL)-6 by hypoxia is mediated by nuclear factor (NF)kappa B and NF-IL6 in cardiac myocytes. Cardiovasc Res 42, 104-112.

48. Taylor CT, Fueki N, Agah A, et al. (1999) Critical role of cAMP response element binding protein expression in hypoxia-elicited induction of epithelial tumor necrosis factor-alpha. J Biol Chem 274, 19447-19454.

49. Yuan G, Nanduri J, Bhasker CR, et al. (2005) Ca2 + /calmodulin kinase-dependent activation of hypoxia inducible factor 1 transcriptional activity in cells subjected to intermittent hypoxia. J Biol Chem 280, 4321-4328.

50. Premkumar DR, Adhikary G, Overholt JL, et al. (2000) Intracellular pathways linking hypoxia to activation of $\mathrm{c}$-fos and AP-1. Adv Exp Med Biol 475, 101-109.

51. Oliver KM, Garvey JF, Ng CT, et al. (2009) Hypoxia activates NF-kB-dependent gene expression through the canonical signaling pathway. Antioxid Redox Signal 11, 2057-2064.

52. Lo YY, Wong JM \& Cruz TF (1996) Reactive oxygen species mediate cytokine activation of c-Jun $\mathrm{NH}_{2}$-terminal kinases. J Biol Chem 271, 15703-15707.

53. Guyton KZ, Liu Y, Gorospe M, et al. (1996) Activation of mitogen-activated protein kinase by $\mathrm{H}_{2} \mathrm{O}_{2}$. Role in cell survival following oxidant injury. $J$ Biol Chem 271, 4138-4142.

54. Abe J, Kusuhara M, Ulevitch RJ, et al. (1996) Big mitogenactivated protein kinase 1 (BMK1) is a redox-sensitive kinase. J Biol Chem 271, 16586-16590.

55. Schmidt KN, Amstad P, Cerutti P, et al. (1995) The role of hydrogen peroxide and superoxide as messengers in the activation of transcription factor NF-kappa B. J Biol Chem 2, 13-22.

56. Gilmore TD (2006) Introduction to NF-кB: players, pathways, perspectives. Oncogene 25, 6680-6684.

57. Cummins EP, Berra E, Comerford KM, et al. (2006) Prolyl hydroxylase-1 negatively regulates IkB kinase-beta giving insight into hypoxia-induced NF-kappaB activity. Proc Natl Acad Sci U S A 103, 18154-18159.

58. Cockman ME, Lancaster DE, Stolze IP, et al. (2006) Posttranslational hydroxylation of ankyrin repeats in IkappaB proteins by the hypoxia-inducible factor (HIF) asparaginyl hydroxylase, factor inhibiting HIF (FIH). Proc Natl Acad Sci U S A 103, 14767-14772.

59. de Vries HE, Witte M, Hondius D, et al. (2008) Nrf2-induced antioxidant protection: a promising target to counteract ROSmediated damage in neurodegenerative disease? Free Radic Biol Med 45, 1375-1383.

60. Tanaka A, Hamada N, Fujita Y, et al. (2010) A novel kavalactone derivative protects against $\mathrm{H}_{2} \mathrm{O}_{2}$-induced PC12 cell death via Nrf2/ARE activation. Bioorg Med Chem 18, 3133-3139.

61. Wruck CJ, Claussen M, Fuhrmann G, et al. (2007) Luteolin protects rat PC12 and C6 cells against MPP + induced toxicity via an ERK dependent Keap1-Nrf2-ARE pathway. J Neural Transm Suppl 72, 57-67. 